\title{
Promovendo o consumo consciente e sustentável de energia elétrica por meio de um projeto de extensão universitária para a educação fundamental
}

\author{
Luiz Fernando Freitas-Gutierres ${ }^{1}$, Cristiano Corrêa Ferreira², Enoque Dutra Garcia ${ }^{3}$, \\ Larissa Mielke Leitzke ${ }^{4}$
}

\begin{abstract}
Resumo: Este trabalho é um relato de experiências obtidas no ano de 2019 durante a execução do projeto "Eficiência Energética na Escola" com uma turma do Segundo Ano do Ensino Fundamental de uma escola localizada em Bagé, Rio Grande do Sul. As ações extensionistas foram promovidas por discentes, docentes e técnicos-administrativos em Educação, vinculados ao Curso de Graduação em Engenharia de Energia da Universidade Federal do Pampa, Campus Bagé. O projeto almejou sensibilizar educandos da Rede de Educação Básica para a concretização de uma cultura voltada ao uso eficiente de energia elétrica. Sob a colaboração dos professores responsáveis pelas turmas, as atividades propostas contemplavam apresentações, discussões, jogos e demonstrações práticas em sala de aula sobre a temática de eficiência e conservação energéticas, e sobre eletricidade aplicada. Este trabalho detalha os procedimentos realizados e as estratégias de ensino-aprendizagem adotadas, como métodos tutoriais, estudos dirigidos em pequenos grupos e práticas pedagógicas gamificadas. Os resultados são discutidos e detalham principalmente as mudanças de hábitos para um uso mais racional da energia elétrica observadas durante e após a execução das ações extensionistas. Essas ações estimulam o interesse pelo Ensino Superior no ambiente escolar; aprimoram a rede de colaboração entre Universidade e escolas; e apoiam a Rede de Educação Básica. Com isso, fomenta-se a divulgação científica e tecnológica, demonstrando o papel e a importância da Universidade para o desenvolvimento local e regional.
\end{abstract}

Palavras-chave: Eficiência energética; Escola; Engenharia de Energia; Educação Básica

\section{Promoting conscious and sustainable consumption of electric energy through a university extension project for elementary education}

\begin{abstract}
This paper aims to report the experience from the project named "Energy Efficiency in the School" with seven-year-old students in a Second Grade classroom in a school located in Bagé, Rio Grande do Sul State, Brazil. In 2019, university extension activities were promoted by students, professors, and technical-administrative employees who work in the education field at the Undergraduate Degree in Energy Engineering at the Federal University of Pampa, Bagé Campus. The project goal is to sensitize Basic Education students to build a culture based on the efficient use of electric energy. In cooperation with the classroom teachers, the proposed activities embrace presentations, discussions, games, and in-class practical demonstrations on energy efficiency and conservation, as well as applied electricity. This paper details the procedures performed by the project team and the learning strategies used in the classroom, such as the tutorial, small-group, and game-based learning techniques. Results are discussed, emphasizing the lifestyle changes for the efficient use of electric energy verified during and after the university extension activities were carried out. This project motivates elementary school students to pursue Higher Education; enhances the collaboration between University and schools; and supports the Basic Education. Thereby, scientific and technological knowledge is disseminated, demonstrating the role played by the University in the local and regional development.
\end{abstract}

Keywords: Energy efficiency; School; Energy Engineering; Basic Education
Originais recebidos em 19 de abril de 2021

Aceito para publicação em 10 de agosto de 2021

1 Professor Adjunto do Departamento de Eletromecânica e Sistemas de Potência (DESP), Universidade Federal de Santa Maria (UFSM), Av. Roraima, 1000, Cidade Universitária, Santa Maria, Rio Grande do Sul, Brasil, CEP 97105-900

https://orcid.org/0000-0002-6254-7306 (autor para correspondência) luiz.gutierres@ufsm.br

2 Professor Associado da Universidade Federal do Pampa, Campus Bagé (UNIPAMPA-CB), Bagé, Rio Grande do Sul, Brasil https://orcid.org/0000-0002-7676-9233 cristianoferreira@unipampa.edu.br 3

Professor Adjunto da Universidade Federal do Pampa, Campus Bagé (UNIPAMPA-CB), Bagé, Rio Grande do Sul, Brasil

https://orcid.org/0000-0002-4741-0037 enoquegarcia@unipampa.edu.br

4

Discente de Engenharia de Energia, Universidade Federal do Pampa, Campus Bagé (UNIPAMPA-CB) larimielke@gmail.com 


\section{Introdução}

A energia elétrica assume, aceleradamente, maior importância para os diversos setores da sociedade, cada vez mais dependentes de disponibilidade energética. Mesclam-se, com isso, preocupações ambientais e crescentes iniciativas políticas ligadas à escassez dos combustíveis fósseis. Nesse contexto, a eficiência e a conservação energéticas destacam-se atualmente na promoção do consumo consciente e sustentável de energia elétrica (Goswami \& Kreith, 2016; Mouraviev \& Koulouri, 2019).

Técnicas de conservação energética visam a reduzir o desperdício e o uso ineficiente de energia, sem comprometer o conforto e tarefas produtivas. Dentre as possíveis práticas de eficiência energética, destacamse: redução do consumo de energia elétrica; otimização dos custos energéticos; e elevação da confiabilidade e da disponibilidade de energia (Mamede Filho, 2011; Sumper \& Baggini, 2012). Um exemplo amplamente conhecido dessas estratégias envolve a substituição de equipamentos por suas respectivas versões mais eficientes. Esse é o caso do uso para a iluminação residencial de lâmpadas dos tipos LED (do inglês, LightEmitting Diode) ou fluorescente, em detrimento das incandescentes, proibidas de serem comercializadas atualmente no território brasileiro (Portaria Interministerial MME/MCT/MDIC $n^{\circ}$ 1.007, de 31 de dezembro de 2010).

Em 2019, constatou-se que o setor residencial brasileiro foi responsável por um consumo de 59\% de eletricidade em edificações quando comparado às construções das categorias comercial e pública (Empresa de Pesquisa Energética, 2020a). Além disso, o setor residencial demonstrou uma participação geral de $26,1 \%$ no consumo de eletricidade no Brasil em 2019, ao passo que o setor industrial representou um consumo de 35,9\% (Empresa de Pesquisa Energética, 2020b). Segundo esses relatórios técnicos, quanto ao uso final energético em habitações, há a predominância de equipamentos elétricos e eletrônicos (com destaque para chuveiros, geladeiras, freezers e máquinas de lavar); da iluminação; e do condicionamento de ar (arescondicionados e ventiladores).

Com os dados elencados acima, nota-se o quão fundamental é incentivar a eficiência e a conservação energéticas no setor residencial. Nesse sentido, uma linha de ação para alavancá-las está na criação de programas educacionais e de conscientização sobre eficiência energética voltados para a Educação Básica, uma recomendação do Plano Nacional de Eficiência Energética (Ministério de Minas e Energia, 2011).

Desde o segundo semestre de 2017, o projeto de extensão universitária intitulado "Eficiência Energética na Escola" é promovido por discentes, docentes e técnicos-administrativos em Educação vinculados ao Curso de Graduação em Engenharia de Energia (CGEE) da Universidade Federal do Pampa, Campus Bagé (UNIPAMPA(B). Por meio de atividades em escolas de Bagé e da Região da Campanha do Rio Grande do Sul, as ações extensionistas almejam sensibilizar educandos dos Ensinos Infantil, Fundamental e Médio para a concretização de uma cultura voltada ao uso eficiente de energia elétrica. Tal conscientização pode implicar uma formação cidadã e uma aplicação de princípios de eficiência energética no dia a dia das comunidades. Essa conscientização possui potencial de provocar a redução do consumo de energia elétrica nas residências dos educandos, principalmente por meio do desenvolvimento de hábitos apropriados de eficiência energética, como relatam Rickinson (2001) e Purnell et al. (2004).

As atividades propostas no projeto abrangem apresentações, discussões e demonstrações práticas em sala de aula, sob a colaboração dos professores da Rede de Educação Básica (REB) responsáveis pelas turmas. Ademais, as atividades alinham-se com a concepção da extensão universitária como um processo educativo, cultural e científico (Encontro de Pró-Reitores de Extensão das Universidades Públicas Brasileiras, 1987). Essa concepção atende à necessidade de um caminho instrumentalizado para a dialética entre teoria e prática, assim como 
favorece a visão integrada do conhecimento social e popular. Dessa forma, viabiliza uma relação ativa e transformadora entre sociedade e Universidade.

Este trabalho é um relato de experiências obtidas no ano de 2019 durante a execução de ações extensionistas com o Segundo Ano do Ensino Fundamental da Escola Municipal de Ensino Fundamental (EMEF) Professor Peri Coronel. Este trabalho está organizado da seguinte forma: a próxima seção detalha os procedimentos metodológicos que regraram as ações extensionistas. Na sequência, resultados, reflexões teóricas e discussões são apresentados aos leitores, seguidos pelas considerações finais e referências bibliográficas.

\section{Procedimentos metodológicos}

O relato de experiências abarca ações de extensão universitária realizadas entre os meses de junho e julho de 2019 na EMEF Professor Peri Coronel, localizada no bairro Nova Esperança em Bagé, Rio Grande do Sul, e nas proximidades da UNIPAMPA-CB. As ações descritas neste trabalho contaram com a participação de vinte e seis estudantes da turma do Segundo Ano do Ensino Fundamental, com idade média de sete anos, supervisionados por duas professoras da referida escola. Cabe salientar que não houve critério de inclusão de estudantes, ou seja, toda a turma participou das atividades propostas. No que concerne à execução, a equipe contou com o docente coordenador, com dois docentes colaboradores, com um discente bolsista do Programa de Fomento à Extensão (PROFEXT) da UNIPAMPA e com quatro discentes voluntários, sendo que todos possuem vínculo com o CGEE e com o Grupo de Estudos Avançados em Engenharia de Energia (GrEEn) da UNIPAMPA-CB.

O projeto "Eficiência Energética na Escola" integra atividades de ensino e de pesquisa, respeitando o conceito de indissociabilidade da tríade Ensino-Pesquisa-Extensão. Nas atividades desenvolvidas na EMEF Professor Peri Coronel houve a cooperação com um projeto de ensino do componente curricular de Tópicos Especiais do CGEE da UNIPAMPA-CB. Essa disciplina foi ofertada em 2018 com o intuito de fabricar peças ou equipamentos por meio de manufatura auxiliada por computador (do inglês, Computer Aided Manufacturing). Um dos resultados dessa disciplina foi o desenvolvimento de um boneco para fins didáticos, utilizado como ferramenta de apoio ao processo de ensino-aprendizagem, como detalhado por Ferreira et al. (2019). Ainda em relação ao ensino, existem interações com o componente curricular de Eficiência e Conservação Energética, ofertado no nono semestre do CGEE. Quanto à pesquisa científica, existem interações com orientações de Iniciação Científica (IC) e de Trabalhos de Conclusão de Curso (TCC).

As ações extensionistas podem ser categorizadas em cinco etapas:

- $\quad$ Etapa 1: Contatos iniciais e levantamento de dados sobre a escola parceira.

- $\quad$ Etapa 2: Planejamento das abordagens e das estratégias de ensino-aprendizagem.

- $\quad$ Etapa 3: Desenvolvimento e adaptação de recursos educacionais.

- $\quad$ Etapa 4: Execução das atividades na escola parceira e coleta de resultados.

- $\quad$ Etapa 5: Análise dos resultados coletados e avaliação de desempenho.

A Etapa 1 corresponde ao contato inicial com a escola, no qual o projeto é apresentado e proposto ao diretor e aos professores. Desde a sua concepção, o projeto "Eficiência Energética na Escola" não estabelece critérios para a escolha das escolas parceiras. Dessa forma, atende escolas públicas ou privadas e turmas dos Ensinos Infantil, Fundamental ou Médio, considerando o interesse das instituições de ensino, assim como a disponibilidade de membros da equipe (docentes colaboradores e discentes da UNIPAMPA-CB) para a realização dos trabalhos. 
A partir do aceite do ator externo e após a definição das turmas beneficiadas, o número total de estudantes e a sua faixa etária são levantados. Além disso, planeja-se um cronograma de abordagens diretas em sala de aula junto aos professores responsáveis pelas turmas. Isso permite o início da Etapa 2, em que há uma definição das estratégias de ensino-aprendizagem que serão adotadas em função, principalmente, da idade média dos estudantes, respeitando ainda as recomendações dos professores da REB.

Em geral, a dinâmica das atividades em sala de aula é expositiva-dialogada, com uso de técnicas de mediação pedagógica (Fontana, 2015). De maneira complementar, são utilizadas estratégias de ensino-aprendizagem tutorial (Caetano et al., 2009), estudos dirigidos em pequenos grupos e práticas pedagógicas gamificadas (Kapp, 2012). Dependendo da faixa etária da turma, optam-se por atividades lúdicas, de caráter visual e/ou com apoio de desenhos. Em todas as abordagens, busca-se favorecer o envolvimento dos estudantes da REB com a sua turma, com a escola e com a comunidade na qual estão inseridos. Almeja-se, desse modo, transpor o conhecimento mediado sobre eficiência energética para os núcleos familiares e para os conhecidos dos estudantes, ampliando o impacto do projeto. No que tange às atividades em sala de aula, essas são realizadas principalmente pelos discentes colaboradores do CGEE e recebem o acompanhamento do docente coordenador e dos professores da REB. Nesse sentido, é fundamental que ao menos um discente colaborador já tenha experiência em sala de aula, que pode ter sido obtida ao participar de edições anteriores do projeto.

Nessa perspectiva, cabe à Etapa 3 o desenvolvimento de recursos educacionais e materiais didáticos (como imagens, vídeos, áudios, apostilas, apresentações, listas de exercícios, entre outros, além da preparação de protótipos, maquetes e demonstrações práticas) sobre eficiência e conservação energéticas. Em diversas situações foi de interesse da escola trabalhar outras temáticas correlatas à eficiência e à conservação energéticas, como tarifação de energia elétrica e fontes alternativas de energia renovável. Assim, materiais didáticos para atender essas demandas foram preparados e obtiveram bons resultados e aceitação.

Como o projeto já foi executado anteriormente aos relatos deste artigo, há uma biblioteca de recursos educacionais, que estão classificados conforme aderência aos Ensinos Infantil, Fundamental e Médio. Dependendo da abordagem planejada, é possível adaptar um material didático destinado, originalmente, ao Ensino Médio para o Ensino Fundamental, por exemplo. Sob esse viés, a execução das atividades planejadas ocorre na Etapa 4, juntamente com a coleta de resultados, que são respostas de formulários; respostas de tarefas propostas; depoimentos de estudantes, de professores e de responsáveis; entre outras possibilidades. É por meio desses resultados que uma avaliação de desempenho pode ser feita na Etapa 5.

Para a turma do Segundo Ano do Ensino Fundamental da EMEF Professor Peri Coronel em 2019, efetuaramse quatro encontros, cada um com uma duração média de 45 minutos. As temáticas abordadas em cada encontro foram as seguintes:

- Primeiro encontro: definição de energia elétrica; esclarecimentos sobre os sistemas elétricos de geração, transmissão e distribuição; e exemplos de usos finais da energia elétrica.

- Segundo encontro: iluminação em instalações elétricas.

- Terceiro encontro: consumo e uso consciente de energia elétrica.

- Quarto encontro: princípios de eficiência e de conservação energéticas.

\section{Resultados e Discussão}

Os relatos de experiências e os resultados são apresentados na sequência e fazem menção aos encontros de maneira individual. Eles são seguidos por uma subseção de discussão e de reflexões. 


\section{Relatos e resultados do primeiro encontro}

No primeiro encontro, o docente coordenador e os discentes colaboradores introduziram-se para a turma e explicaram o que é o projeto e quais são as suas metas. As apresentações abrangeram também informações sobre a UNIPAMPA-CB, o CGEE e o GrEEn.

A definição de energia elétrica foi abordada por meio de uma apresentação projetada, contendo ilustrações, vídeos $^{\underline{1}}$ e animações, além de explicações conceituais sobre tensão e corrente elétricas terem sido mediadas. Em seguida, discutiu-se sobre os principais tipos de fontes de geração de energia elétrica presentes no Brasil, a saber: hidroelétrica, termoelétrica, eólica e solar fotovoltaica. Por meio de mediação pedagógica, os estudantes foram conduzidos a comentar sobre os tipos de fontes de geração de energia elétrica e se já haviam visto unidades geradoras, como uma torre eólica ou uma usina termoelétrica.

Notou-se que os estudantes conseguiram relacionar as explicações teóricas com referências regionais como as usinas termoelétricas de Candiota (município próximo de Bagé); parques eólicos e o complexo eólico de Osório (localizado no Litoral Gaúcho); e instalações com painéis solares fotovoltaicos. Houve bastante receptividade e interação da turma sobre esse assunto e notou-se que os estudantes conseguiam, em sua maioria, relacionar a geração de energia elétrica com os usos finais em suas residências. Todavia, verificaramse, também, dificuldades em compreender como a transmissão e a distribuição de energia elétrica ocorrem. Outro tópico que levantou dificuldades estava relacionado com os impactos que a geração de energia elétrica provoca no meio ambiente, conforme cada tipo de energia. Em outras palavras, houve confusões em diferenciar fontes de energia renováveis e não renováveis.

De modo a colaborar com a solução das dificuldades apontadas anteriormente, uma maquete contendo representações de um aerogerador, de um painel solar fotovoltaico e de unidades consumidoras foi construída. A Figura 1 ilustra a maquete que, dependendo da intensidade do vento ou da iluminação, demonstra maior ou menor capacidade de geração de energia elétrica, sinalizada por meio da intensidade luminosa dos LEDs presentes no interior das casas. Explicações adicionais, sobre o funcionamento da maquete e com a utilização dos vídeos didáticos, foram oferecidas sobre os tópicos em que houve dificuldades de entendimento, no intuito de reforçar o aprendizado adquirido e de suprir as lacunas de assimilação do conhecimento.

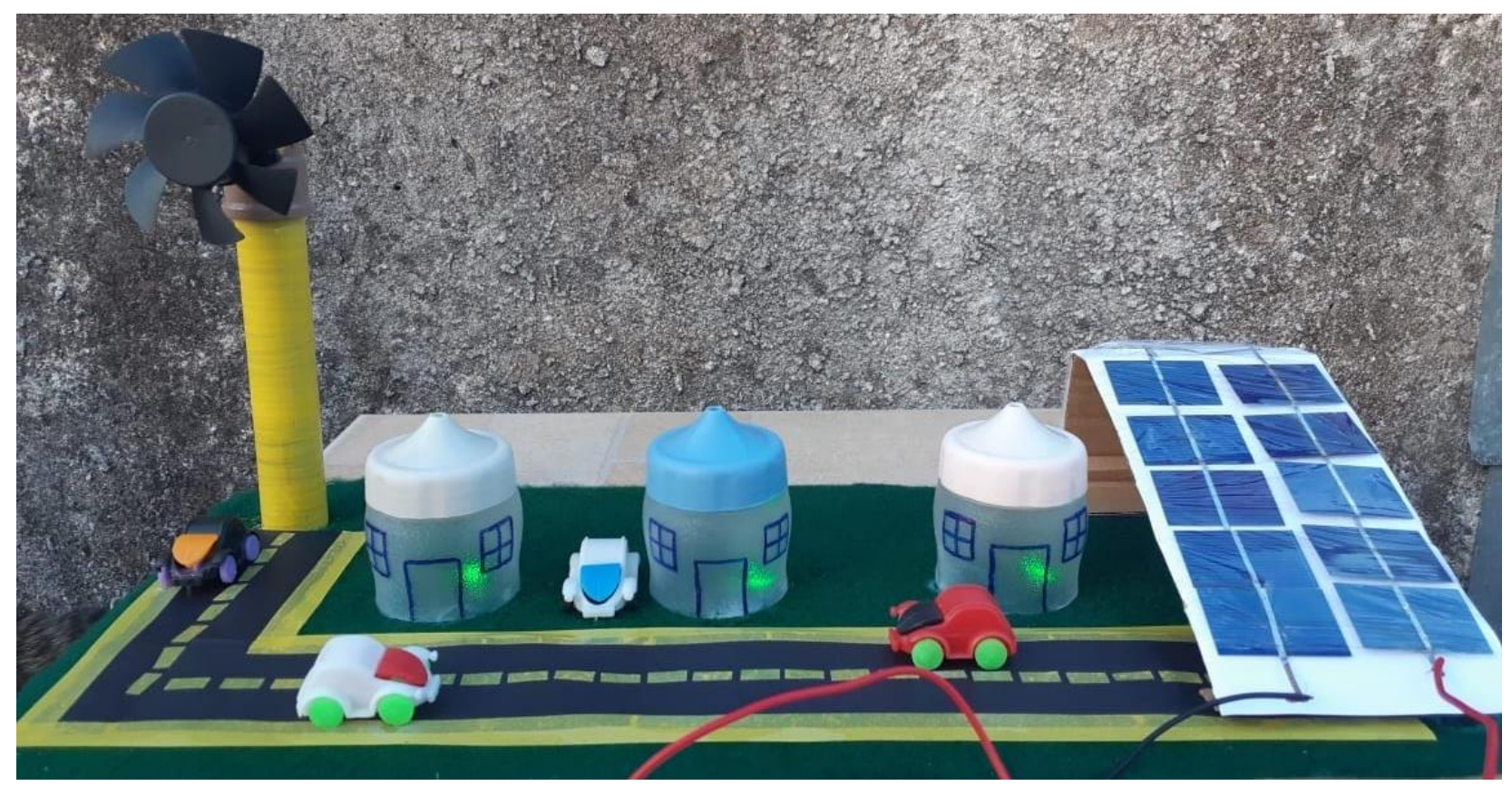

Figura 1. Maquete sobre fontes renováveis de energia elétrica. 
Ao final, uma atividade avaliativa foi proposta, a qual consistia em relacionar imagens que faziam menção aos tipos de geração de energia elétrica com os seus respectivos recursos naturais e fontes (por exemplo, vento com energia eólica). Observou-se que vinte estudantes (de um total de vinte e quatro) acertaram integralmente a avaliação. Apenas quatro estudantes desempenharam alguma associação incorreta entre as imagens e, de maneira tutorada, as correções foram feitas.

\section{Relatos e resultados do segundo encontro}

A ênfase do segundo encontro esteve na iluminação geral de instalações elétricas, mais especificamente nos tipos de lâmpadas e nas suas diferenças. Aspectos de eficiência energética foram destacados em relação ao rendimento luminoso, aos hábitos inadequados e à falta de aproveitamento da iluminação natural. Além disso, realizaram-se demonstrações práticas com lâmpadas dos tipos incandescente, fluorescente e LED.

Como ilustra a Figura 2, um jogo de dominó, que envolvia associações de peças coloridas representando os tipos de lâmpadas, foi proposto para pequenos grupos de estudantes. Como resultado, tanto as demonstrações práticas quanto o jogo de dominó evidenciaram bom aproveitamento por parte da turma. As discussões sobre hábitos inadequados de iluminação residencial, nesse sentido, levaram os próprios estudantes a revelarem situações em suas casas, como pontos de iluminação ligados desnecessariamente. Aproveitou-se esse fato para reforçar medidas de combate ao desperdício e de redução de custos.

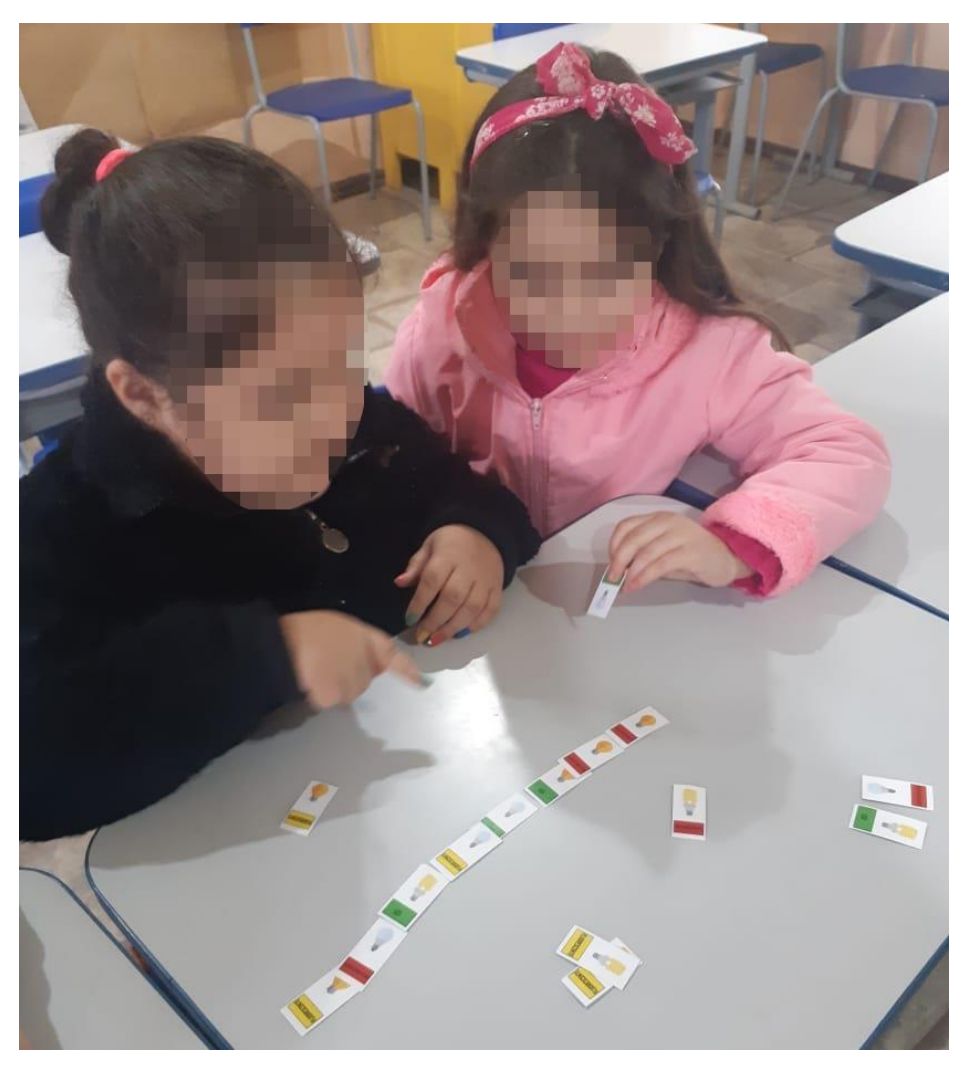

Figura 2. Jogo de dominó sobre os tipos de lâmpadas. 


\section{Relatos e resultados do terceiro encontro}

A temática abordada no terceiro encontro envolveu consumo e uso consciente de energia elétrica. Como ilustra a Figura 3, um jogo de tabuleiro foi desenvolvido para tratar sobre eficiência energética e sobre boas práticas para o uso racional de eletricidade. Divididos em pequenos grupos, os estudantes deveriam percorrer o caminho visto na Figura 3 em turnos, com avanço a partir da rolagem de dados e com competição para chegar ao centro do tabuleiro. Durante o percurso existem obstáculos que demandavam a resposta do jogador a uma pergunta, as quais foram adaptadas para corresponderem a medidas adequadas ou não de uso racional de eletricidade, exigindo uma resposta como "certo" ou "errado" e provocando vantagens ou desvantagens no jogo.

Observou-se, assim, que a prática pedagógica gamificada proporcionou considerável interação com a turma e cativou o interesse dos estudantes, principalmente por elencar situações cotidianas, como tomar banho demoradamente e como manter a porta da geladeira aberta por muito tempo. Desse modo, concluiu-se que os resultados foram satisfatórios e que erros não foram observados. Por fim, um crachá de "Fiscal de Energia" foi entregue para cada estudante, incentivando que conversassem com os seus familiares sobre as boas práticas estudadas e que observassem a existência de casos de desperdício em suas casas.

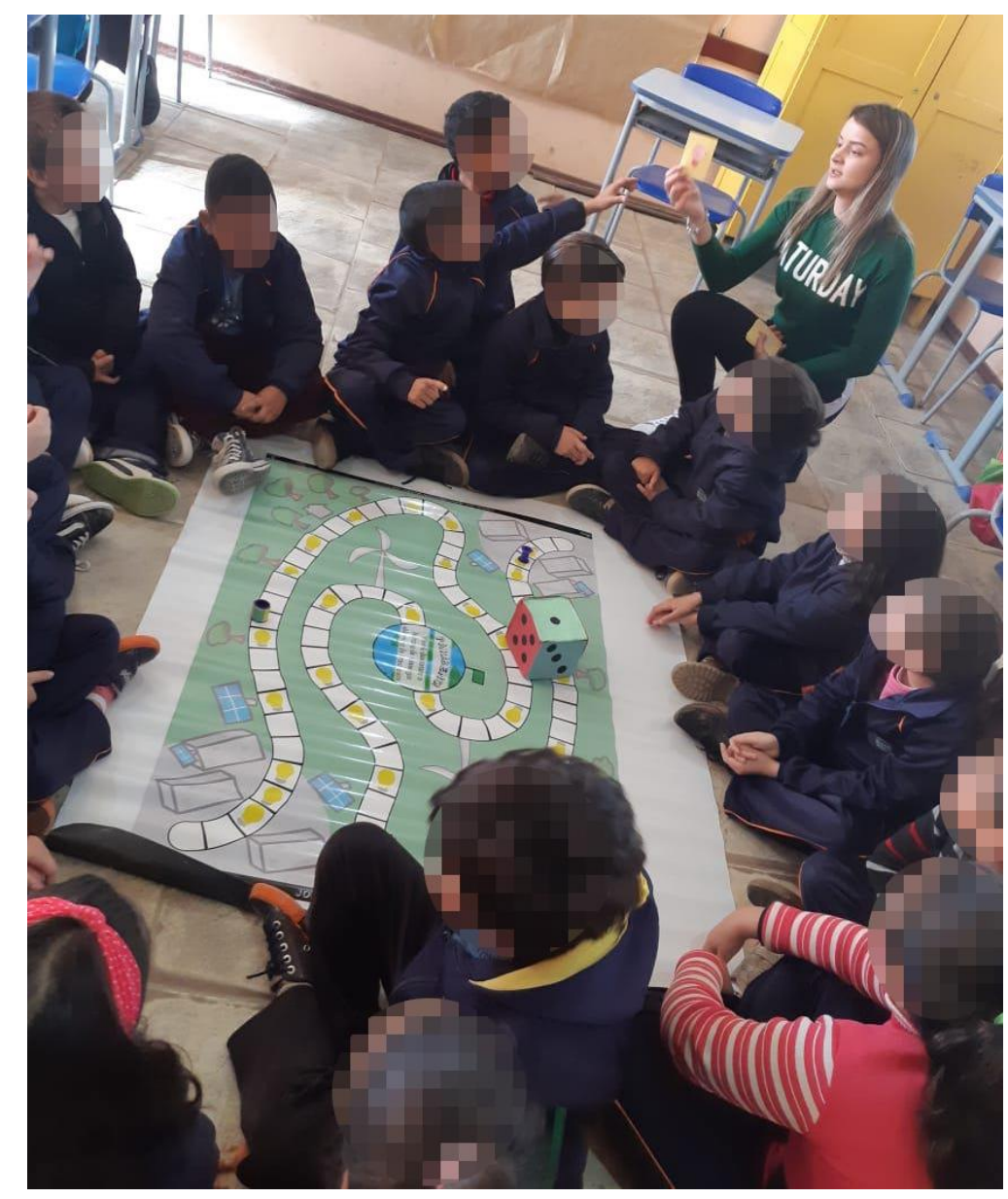

Figura 3. Jogo de tabuleiro sobre boas práticas para o uso racional de eletricidade. 
Outra atividade proposta foi o uso de um boneco didático, que foi desenvolvido por um projeto de ensino do componente curricular de Tópicos Especiais do CGEE da UNIPAMPA-CB (Ferreira et al., 2019). Como ilustra a Figura 4, o boneco didático é um instrumento lúdico que almeja facilitar a atenção e o engajamento de crianças com as ações de ensino do projeto "Eficiência Energética na Escola". O boneco didático é composto por uma envoltória fabricada por meio de tecnologias de modelagem tridimensional e prototipagem por impressora 3D. Dentro dessa envoltória há uma lâmpada que proporciona um efeito visual externo ao boneco (assemelhase a uma luminária) e um medidor de consumo de energia elétrica. O boneco didático foi entregue à turma e ficou por uma semana em sala de aula. O objetivo principal era que os estudantes cuidassem dele, mantendoo ligado e iluminado apenas quando necessário, devendo desligá-lo quando saíssem do local (recreio e término da aula, por exemplo). Ademais, foi combinado com as professoras da REB responsáveis pela turma que registrassem as reações dos estudantes e também as possíveis ocasiões em que boneco permanecesse ligado erroneamente. Além disso, o boneco possui um medidor de consumo de energia elétrica em seu interior, que registra também as ações de ligar e desligar da lâmpada. Dessa forma, o medidor monitora se o boneco didático está ligado ou não durante o horário de recreio e após o final da aula.

\section{Relatos e resultados do quarto encontro}

O quarto encontro tratou sobre princípios de eficiência e de conservação energéticas, sobretudo em aplicações residenciais. As explicações basearam-se no uso de uma maquete de uma instalação elétrica residencial² (Figura 5) capaz de simular em tamanho reduzido o funcionamento de lâmpadas e de eletrodomésticos, controlados por meio de interruptores externos. A maquete detém um relógio-medidor eletromecânico de energia elétrica que, por meio do giro de um disco de metal movido por força eletromagnética, permite visualizar o nível de consumo. Quanto maior a quantidade de equipamentos ligados no interior da maquete (ou se eletrodomésticos com maior capacidade de consumo são ligados), maior será a quantidade de voltas desse disco de metal. Assim, há um aspecto didático relacionado a isso e explicações são proporcionadas aos estudantes, alinhadas também às questões sobre tarifação de energia elétrica e sobre redução de custos energéticos.

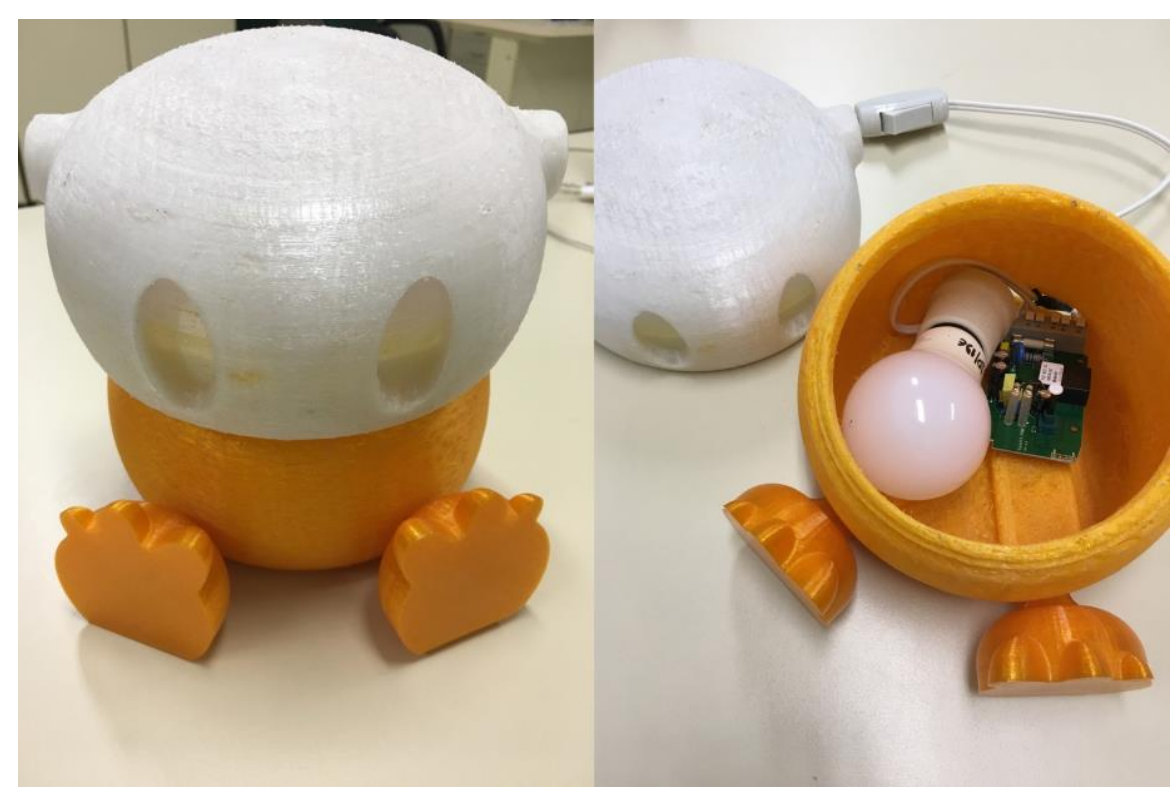

Figura 4. Boneco didático. 


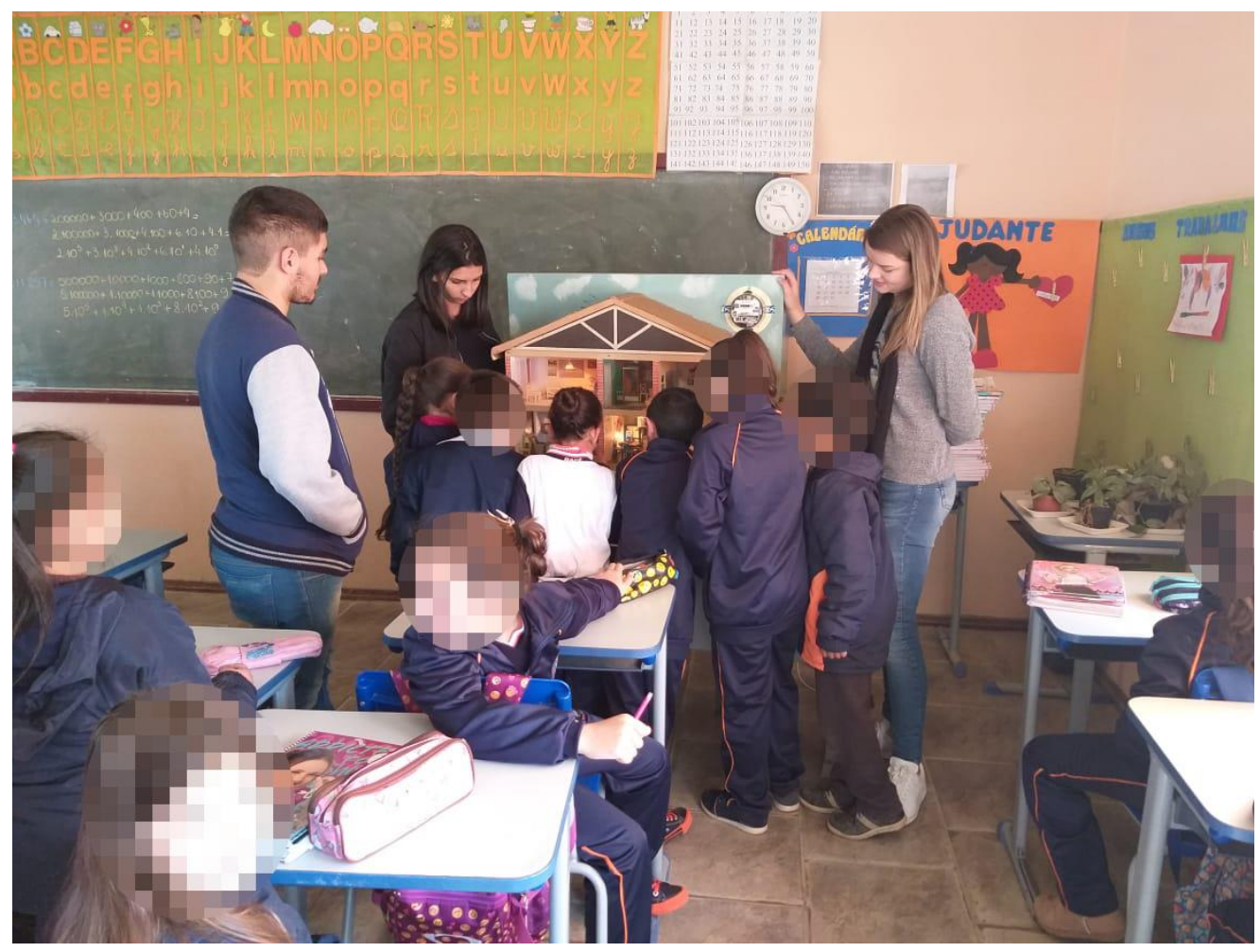

Figura 5. Atividade com a maquete de uma instalação elétrica residencial.

Ainda sob essa perspectiva, uma atividade avaliativa de verdadeiro ou falso foi proposta, em que ações adequadas ou inadequadas de uso final da energia elétrica eram sugeridas aos estudantes (a exemplo de não aproveitar a iluminação natural e apagar as lâmpadas quando sair de um dormitório), que deveriam julgá-las com base nos estudos realizados durante a execução do projeto na turma. Um desempenho convincente foi constatado, uma vez que apenas um dos estudantes presentes demonstrou erros na apreciação das proposições. Após algumas discussões finais, as ações extensionistas foram encerradas e a equipe executora despediu-se da turma.

\section{Relatos de uma professora da REB responsável pela turma}

Após o encerramento das atividades, depoimentos de uma professora responsável pela turma foram coletados. Dentre as professoras da REB que tiveram contato com a equipe executora, uma colaborou por mais tempo com as ações e, por isso, optou-se por realizar uma entrevista com ela. O depoimento foi estruturado em forma de questionário, foi gravado e, em seguida, transcrito. Na sequência, alguns trechos são apresentados, com recortes de cinco perguntas selecionadas e que são de interesse a este trabalho:

a) Qual o conhecimento prévio dos estudantes sobre eletricidade e sobre eficiência energética antes da execução das ações extensionistas?

[...] O que eu percebo é que eles não tinham o cuidado com o consumo de energia [...], a questão prática de logística de sala de aula mesmo, quando trocam de sala, eles nunca tinham essa preocupação de desligar o ventilador, de desligar a luz [...]. Provavelmente, não tinham em casa. (professora da REB). 
b) Os conceitos de energia elétrica e de eficiência energética já haviam sido trabalhados em sala de aula?

[...] Não, os conceitos, os exemplos práticos, não, somente de uma forma muito abrangente. [...] Foi só a partir do projeto mesmo. (professora da REB).

c) É fácil encontrar recursos educacionais sobre eletricidade e sobre eficiência energética na Internet, em livros e em apostilas?

Pra esse nível de ensino, não. Não é fácil [...]. (professora da REB).

d) Qual o impacto que o projeto apresentou nos estudantes?

A economia referente a energia, o cuidado, fiscalizar, tanto a professora quanto entre eles. Eles dizem que em casa eles têm esse cuidado também e isso está principalmente atrelado ao orçamento doméstico. E não só por isso, uma questão financeira, mas uma questão de consciência mesmo [...]. Eles são pequenos, né? Têm sete anos. Mas, eles são multiplicadores. (professora da REB).

e) Como foi a dinâmica dos estudantes com o boneco didático em sala de aula?

Nenhum dia... Nenhum, alguém deixou de dizer, dos alunos da sala... sem eu direcionar, entendeu? [...] Nenhum dia, algum deles deixou de desligar. Eles se preocuparam, sempre! Sempre algum deles lembrava. E sem eu chamar atenção para aquilo [...] Como um recurso a mais ele é válido [...]. Algo lúdico, especialmente para os pequenos. (professora da REB).

\section{Discussão e reflexões teóricas}

Os relatos descritos anteriormente permitem reflexões quanto às intervenções didáticas realizadas. Apesar de grande parte dos encontros demonstrar uma estratégia de ensino-aprendizagem expositiva-dialogada, em todos houve algum tipo de ação que promoveu interatividade e incentivou proatividade. Em dois encontros, a saber, houve o uso de técnicas de ensino gamificadas que despertaram, nitidamente, o interesse dos estudantes da REB, gerando questionamentos.

A cada encontro realizado, houve maior integração e sensação de pertencimento com a turma, facilitando a realização das ações extensionistas. Além disso, a utilização do boneco didático demonstrou ser uma prática pedagógica inovadora, tanto no aspecto de ensino quanto no de avaliação e de reforço da aprendizagem. Ademais, serviu, também, para estabelecer uma relação entre o conhecimento que os estudantes assimilaram e a prática que tiveram, provocando a necessidade de uma ação e de uma rotina de trabalho pedagógico em sala de aula, o que é fundamental para o desenvolvimento de um hábito adequado (ou uma mudança de hábito) quanto ao uso consciente de energia elétrica. Essa interação refletiu, desse modo, em correções de comportamentos nos núcleos familiares de cada estudante, como aponta a resposta da professora para o item "d" na subseção anterior.

O depoimento da professora responsável pela turma revelou que os estudantes passaram a ficar mais atentos no uso da iluminação em sala de aula e de aparelhos eletroeletrônicos em geral, evitando mantê-los ligados desnecessariamente. Essa nova prática acaba por favorecer o engajamento dos estudantes com a escola, colaborando para o desenvolvimento de princípios de responsabilidade e de cidadania.

Como discutido por Purnell et al. (2004), diferentes fatores podem influenciar nos impactos proporcionados por projetos semelhantes ao relatado neste trabalho, como: o tamanho da população atingida diretamente pelas ações; o envolvimento das famílias com os seus filhos e com a escola; o quão ativa e participativa é a comunidade local; e a consecução dos estudos e da prática de princípios de eficiência energética na escola. Dessa forma, avaliar, quantitativamente, a repercussão do projeto em mudanças comportamentais dos estudantes e de seus núcleos de convivência não é algo de fácil efetivação. Todavia, as atividades realizadas 
durante os quatro encontros e o depoimento da professora indicam que os estudantes demonstraram hábitos alinhados à eficiência energética dentro da escola e, possivelmente, em suas residências. Assim, reforça-se que o projeto contribuiu para o desenvolvimento de uma cultura voltada ao uso eficiente de energia elétrica nos estudantes e, indiretamente, em seus familiares ou responsáveis.

Para aprimorar e sustentar as mudanças comportamentais observadas, recomendou-se que a escola disponha pôsteres com informações sobre o uso consciente de energia elétrica próximo de interruptores e em locais de grande movimentação; realize palestras e feiras de ciência sobre eficiência energética; e desenvolva um plano com diretrizes e orientações estratégicas de eficiência energética. Essas sugestões podem ser alavancadas pela escola como uma de suas prioridades pedagógicas. Dessa maneira, as mudanças de hábitos tenderão a ser perpetuadas e, além disso, espera-se verificar reduções de custos energéticos a médio e longo prazos na escola. O projeto busca, à vista disso, provocar um efeito multiplicador e de autonomia nas escolas parceiras, consolidando novos agentes atuantes em prol da eficiência e da conservação energéticas.

No que tange aos discentes colaboradores do CGEE, o projeto permite que eles participem de atividades que, apesar da natureza de extensão, possuam também características de ensino e de pesquisa científica, com foco em eficiência energética e em eletricidade aplicada. Tais discentes têm contato direto com a comunidade de Bagé e da Região da Campanha do Rio Grande do Sul, estabelecendo uma nova visão dos conhecimentos estudados na Universidade e podendo aplicá-los em nível regional. Assim, solidificam suas habilidades profissionais, mantendo vínculos com o contexto local e se posicionam como cidadãos ativos, participativos e conscientes.

Ainda nesse contexto, o projeto auxilia na formação científica de estudantes do Ensino Fundamental, colaborando para o desenvolvimento de habilidades básicas referentes à eletricidade aplicada e à eficiência energética. Isso se justifica pela concretização de capacidades de observação, de análise, de compreensão e de raciocínio crítico e criativo sobre essas temáticas nos estudantes da REB. As ações extensionistas permitem, ademais, a divulgação sobre a UNIPAMPA-CB e sobre o CGEE, além de promoverem o interesse pelo Ensino Superior no ambiente escolar e de aprimorarem a rede de colaboração entre Universidade e escolas, apoiando, também, a REB. Com isso, fomenta-se a divulgação científica e tecnológica, demonstrando o papel e a importância da Universidade para o desenvolvimento local e regional.

Concatenado a isso, observou-se, na literatura especializada, que outros projetos apresentaram resultados similares, em maior ou menor grau, com os relatados neste trabalho, como em Casara et al. (2015), Ishikura et al. (2017), Falcão e Caldas (2018), Baron et al. (2020), Colombo Junior et al. (2020) e Dorigo et al. (2020). Neste trabalho, a troca de saberes entre sociedade e Universidade ocorre com ênfase em eletricidade aplicada e em eficiência energética, o que também é trabalhado por Casara et al. (2015) e Falcão e Caldas (2018) com foco em outros temas centrais. Assim sendo, almeja-se, por meio da extensão universitária, estabelecer um diálogo agregador e de transformação, colaborando com a escolha futura de uma possível carreira profissional dos estudantes da REB e com a democratização dos conhecimentos acadêmicos. Nessa perspectiva, há também a promoção da divulgação científica em escolas, como ocorre nos trabalhos de Ishikura et al. (2017) e de Dorigo et al. (2020). De forma complementar, projetos de extensão universitária junto a escolas motivam, em geral, a inserção de metodologias pedagógicas inovadoras em sala de aula, como discutido por Colombo Júnior et al. (2020). Finalmente, questões sob o prisma da sustentabilidade socioambiental e do uso adequado de recursos naturais são relatadas por Baron et al. (2020).

Por conseguinte, no que corresponde ao projeto "Eficiência Energética na Escola", executaram-se atividades envolvendo temáticas que, frente à geração de energia e à utilização de combustíveis fósseis com os problemas ambientais associados a essas conjunturas, têm adquirido importância. Portanto, colabora-se com a inserção e consolidação de novos conhecimentos no contexto escolar, contribuindo para a construção conjunta, 
reflexiva e responsável de uma formação que prepara os estudantes da REB e universitários para os desafios impostos por uma sociedade em contínua transformação.

Por fim, elencam-se as principais dificuldades atreladas à execução das ações extensionistas:

- Rotatividade dos membros da equipe universitária, uma vez que o grupo de trabalho é constituído principalmente por discentes voluntários.

- Desenvolvimento e adequação de recursos educacionais, dada a falta de experiência dos membros da equipe com o exercício pedagógico, o que se aplica também à execução das atividades em sala de aula.

- Transporte da equipe executora e de recursos educacionais pesados.

\section{Considerações finais}

O projeto "Eficiência Energética na Escola" foi de grande relevância para o público participante, estudantes e professores da REB associados com a turma do Segundo Ano do Ensino Fundamental da EMEF Professor Peri Coronel em 2019. Tópicos sobre eficiência e conservação energéticas foram abordados em sala de aula de maneira satisfatória, demonstrando indiretamente um efeito multiplicador na comunidade por meio de hábitos adequados e racionais no uso final da eletricidade.

O projeto vai ao encontro das políticas de extensão da UNIPAMPA, almejando uma relação transformadora entre a Universidade e a sociedade. Portanto, a partir dos relatos de experiência contidos neste trabalho, espera-se incentivar o surgimento e o fortalecimento de ações extensionistas em ambiente escolar na área da Engenharia de Energia, sendo que os resultados verificados são de grande proveito, tanto para as escolas quanto para os Cursos de Graduação envolvidos, e para a Universidade como um todo.

\section{Agradecimentos}

Este trabalho foi financiado parcialmente pelo Programa de Fomento à Extensão (PROFEXT, Edital $N^{\circ}$ 68/2019) por meio da Pró-Reitoria de Extensão e Cultura (PROEXT) da Universidade Federal do Pampa (UNIPAMPA). Os autores agradecem à Companhia Estadual de Distribuição de Energia Elétrica (CEEE-D) na figura da Gerência da Campanha por ceder a maquete de uma instalação elétrica residencial. Além disso, agradecemos à Escola Municipal de Ensino Fundamental Professor Peri Coronel por aceitar a realização dos trabalhos de extensão universitária em suas dependências.

\section{Contribuição de cada autor}

O autor L.F.F.G. foi docente coordenador do projeto. Os autores E.D.G. e C.C.F. colaboraram com a execução das ações extensionistas. A autora L.M.L. foi bolsista pelo Programa de Fomento à Extensão (PROFEXT) da UNIPAMPA e liderou a execução das atividades na escola. Todos os autores participaram da redação e da revisão intelectual crítica deste artigo. 


\section{Notas}

1. Vídeos com conteúdo infantil sobre eletricidade aplicada, como neste desenho animado: https://www.youtube.com/watch?v=8ti6FtlvMoc

2. Maquete de instalação elétrica residencial cedida pela Companhia Estadual de Distribuição de Energia Elétrica (CEEED).

\section{Referências}

Baron, D., Momberg da Silva, C. G. M., Almeida, S. C. O., Cordeiro, M. M., \& Helmer, E. A. (2020). Popularização da sustentabilidade: Análise de uma integração ensino médio-graduação. Revista Brasileira de Extensão Universitária, 11(1), 97-112.

Caetano, A. P., Simão, A. M. V., \& Freire, I. (2009). Tutoria e mediação em educação. Lisboa: Educa.

Casara, V. P., Dalla Vecchia, R., Binotto, R. R., Rodrigues, R., Daga, O., Bianchi, M., ... \& Quast, L. B. (2015). A engenharia na escola. Revista Brasileira de Extensão Universitária, 6(1), 43-51.

Colombo Junior, P. D., Ovigli, D. F. B., \& Alves, S. E. (2020). Iniciação à docência em Física e as indagações de estudantes da educação básica - Um relato. Revista Brasileira de Extensão Universitária, 11(3), 288-300.

Dorigo, A. S., Anjos, A., Marcato, A. C. C., Pires-Silva, D., Gonçalves, L. R., Anholeto, L. A., ... \& Cabral-de-Mello, D. C. (2020). Projeto Primeiros Passos na Ciência: Rompendo barreiras sociais e estreitando laços entre a comunidade acadêmica e o Ensino Médio público. Revista Brasileira de Extensão Universitária, 11(1), 47-59.

Empresa de Pesquisa Energética (EPE). (2020a). Atlas da Eficiência Energética - Brasil 2020. Rio de Janeiro: EPE. Recuperado de https://bit.ly/3v3F2nD

Empresa de Pesquisa Energética (EPE). (2020b). Balanço Energético Nacional 2020: Ano Base 2019. Rio de Janeiro: EPE. Recuperado de https://bit.ly/2PCzpwo

Encontro de Pró-Reitores de Extensão das Universidades Públicas Brasileiras (1987). Conceito de Extensão, Institucionalização e Financiamento. Brasília: Universidade de Brasília. Recuperado de https://bit.ly/3rBQF3c

Falcão, N. M., \& Caldas, E. C. R. (2018). Diálogos sobre a escolha profissional: A aproximação entre o estudante da escola pública de ensino médio e a universidade. Revista Brasileira de Extensão Universitária, 9(3), 147-156.

Ferreira, C. C., Freitas-Gutierres, L. F., Cunha, P. S., \& Mendes, D. R (2019). Prototipagem 3D na componente curricular de tópicos especiais como apoio às ações extensionistas em escolas de Bagé. Revista de Ensino de Engenharia, 38(1), 34-42.

Fontana, R. A. C. (2015). Mediação pedagógica na sala de aula. 4. ed. Campinas: Autores Associados.

Goswami, D. Y., \& Kreith, F. (2016). Energy efficiency and renewable energy handbook. 2. ed. Boca Raton: CRC Press.

Ishikura, J. I., Cordeiro, C. T., da Silva, E. C., Bueno, G. P., dos Santos, L. G., \& Oliveira, S. T. (2017). Mini-hospital veterinário: Guarda responsável, bem estar animal, zoonoses e proteção à fauna exótica. Revista Brasileira de Extensão Universitária, 8(1), 23-30.

Kapp, K. M. (2012). The Gamification of learning and instruction: Game-based methods and strategies for training and education. San Francisco: Pfeiffer-John Wiley \& Sons.

Mamede Filho, J. (2011). Instalações Elétricas Industriais (8. ed., reimpressão). Rio de Janeiro: LTC.

Ministério de Minas e Energia (MME). (2011). Plano Nacional de Eficiência Energética: Premissas e diretrizes básicas. Brasília: Ministério de Minas e Energia (MME). Recuperado de https://bit.ly/2VB7qAy

Mouraviev, N., \& Koulouri, A. (2019). Energy security: Policy challenges and solutions for resource efficiency. Cham: Springer.

Purnell, K., Sinclair, M., \& Gralton, A. (2004). Sustainable schools: Making energy efficiency a lifestyle priority. Australian Journal of Environmental Education, 20(2), 81-91. 
Rickinson, M. (2001). Learners and learning in environmental education: A critical review of the evidence. Environmental Education Research, 7(3), 207-320.

Sumper, A., \& Baggini, A. (2012). Electrical energy efficiency: Technologies and applications. Chichester: John Wiley \& Sons.

Como citar este artigo:

Freitas-Gutierres, L. F., Ferreira, C. C., Garcia, E. D., \& Leitzke, L. M. (2021). Promovendo o consumo consciente e sustentável de energia elétrica por meio de um projeto de extensão universitária para a educação fundamental. Revista Brasileira de Extensão Universitária, 12(3), 297-310. https://periodicos.uffs.edu.br/index.php/RBEU/article/view/ 12346/pdf 